\title{
Shifting management of a community volunteer system for improved child health outcomes: results from an operations research study in Burundi
}

\author{
Jennifer Weiss ${ }^{* *}$, Raphael Makonnen², Delphin Sula ${ }^{3}$
}

\begin{abstract}
Background: Community-based strategies that foster frequent contact between caregivers of children under five and provide credible sources of health information are essential to improve child survival. Care Groups are a community-based implementation strategy for the delivery of social and behavior change interventions. This study assessed if supervision of Care Group activities by Ministry of Health $(\mathrm{MOH})$ personnel could achieve the same child health outcomes as supervision provided by specialized non-governmental organization (NGO) staff.

Methods: The study was a pretest-posttest quasi-experimental design implemented in Burundi. A total of $45 \mathrm{MOH}-$ led Care Groups with 478 Care Group Volunteers (CGVs) were established in the intervention area; and 50 NGO-led Care Groups with 509 CGVs were formed in the comparison area. Data were collected from 593 and 700 mothers of children 0-23 months at baseline and endline, respectively. Pearson's chi-squared test and difference-indifference analysis assessed changes in 40 child health and nutrition outcomes. A qualitative process evaluation was also conducted midway through the study.

Results: The MOH-led Care Group model performed at least as well as the NGO-led model in achieving specific child health and nutrition outcomes. Mothers of children 0-23 months in the intervention and comparison sites reported similar levels of knowledge and practices for 38 of 40 dependent variables measured in the study, and these results remained unchanged after accounting for differences in the indicator values at baseline. Process monitoring data confirmed that the MOH-led Care Group model and the NGO-led Care Group model were implemented with similar intervention strength.

Conclusions: The study demonstrated that behavior change interventions traditionally led by NGOs can be implemented through the existing $\mathrm{MOH}$ systems and achieve similar results, thereby increasing the potential for sustainable child health outcomes. Future research on the $\mathrm{MOH}$-led Care Group model is required to systematically document all inputs and monetary costs borne by the $\mathrm{MOH}$ to implement the model.
\end{abstract}

\section{Background}

Strengthening community health systems through a welltrained and supported workforce is an important step to reducing child mortality, addressing inequity, and attaining universal health coverage [1,2]. As a critical cadre of the health workforce, Community Health Workers (CHWs)

\footnotetext{
* Correspondence: jennifer.weiss@concern.net

'Concern Worldwide, US, 355 Lexington Ave, $19^{\text {th }}$ Floor New York, NY 10017, USA

Full list of author information is available at the end of the article
}

have made significant contributions towards child survival priorities in several low income countries [3]. There is substantial evidence documenting CHWs' effectiveness in generating demand for health services and expanding coverage of key child health preventive practices in underserved populations through intensive community mobilization and routine, systematic household visitation $[4,5]$. Community-based strategies that foster frequent contact between caregivers of children under five years of age and credible sources of health information, including CHWs, 
are essential to achieve behavior change outcomes and sustained improvements in household practices [6,7]. However despite their potential, CHWs may face unmanageable workloads and large catchment areas, which limit their effectiveness for optimal behavior change [8]. In addition, while normative guidance exists, there is a lack of documented evidence on appropriate strategies to sustainably integrate various $\mathrm{CHW}$ cadres into the formal health system $[9,10]$.

The Care Group Community Volunteer System is a community-based implementation strategy for the delivery of social and behavior change interventions [11]. The linchpin of this approach is the Care Group Volunteer (CGV); a woman living in the community who is elected by her peers and who herself has a child under the age of five years. The CGV participates in monthly meetings of her Care Group to receive lessons in a specific child health topic, and is then responsible for visiting her 10-12 neighbour households with interpersonal behavior change communication on the child health topic on at least a monthly basis. By collectively 'saturating' the target area, Care Groups have contributed to improved child health outcomes in a number of contexts $[12,13]$.

Care Groups are facilitated by and through non-governmental organization (NGO) projects and project staff, and CGVs are trained and supervised by full-time project staff members called 'Promoters'. Ministry of Health $(\mathrm{MOH})$ leadership is necessary for scaling-up and sustaining community health initiatives [14]. Until this time, NGOs have not attempted to meaningfully collaborate with MOU counterparts to integrate the Care Group model into existing government delivery systems, with supervision of all Care Group activities remaining under the direction of full-time NGO staff [15].

We therefore tested the effect of replacing paid NGO supervisors with $\mathrm{MOH}$ supervisors who added Care Group supervision to their regular activities. Under this $\mathrm{MOH}-\mathrm{led}$ Care Group model, CGVs are trained and supervised by a cadre of MOH-recognized CHWs, who are unpaid. The CHWs are in turn supervised by the head nurse at the health facility, who is in turn supervised by the District Health Team. The objective of the study was to determine if supervision of Care Group activities by $\mathrm{MOH}$ personnel could achieve the same results as supervision provided by specialized NGO staff.

\section{Methods \\ Study design}

The study was a pretest-posttest quasi-experimental design implemented in Burundi. The study was implemented in Bukinanyana Commune, which has a total population of approximately 110,000 and is one of three mountainous and rural communes in Mabayi Health District. Bukinanyana was selected in collaboration with district officials as the study location as it is the most populous and underserved of the three communes in the district, has no other NGOs active in the commune, and has the most limited availability of health services. The five zones within Bukinanyana Commune were grouped into two clusters based on population size (cluster one consisted of three zones and cluster two consisted of two zones). Each cluster was then randomly assigned by coin toss to either the intervention area (MOH-led Care Groups) or comparison area (NGO-led Care Groups). The intervention and comparison areas were contiguous. In the intervention area, 45 Care Groups with 478 CGVs were established. These $\mathrm{MOH}-$ led Care Groups were supervised by $26 \mathrm{CHWs}$, who were in turn supervised by the head nurse at each of the three health facilities within the intervention area. In the comparison area, 51 Care Groups with 503 CGVs were formed. These NGO-led Care Groups were supervised by six NGO supervisors. The head nurse at each of the four health facilities and the 34 CHWs within the comparison area were also oriented on the NGO-led Care Group model and encouraged to participate in Care Group activities.

\section{Implementation of the intervention}

Care Group activities commenced in June 2011 in both study areas and were implemented according to Care Group standards [16] over a period of two years. Care Group meetings were held twice per month. In addition, CGVs were asked to conduct home visits to each of her 10-12 neighbouring households at least once per month, during which they provided health promotion messages, screened for acute malnutrition, and collected vital events data. In the MOH-led model, NGO staff first trained the District Health Team and health facility staff on the overall Care Group model and in the use of training materials with CHWs and CGVs. NGO staff also provided technical support as needed over the course of the study to the District Health Team and health facility staff to facilitate their leadership of Care Group activities.

Table 1 illustrates the key differences in $\mathrm{MOH}$-led and NGO-led Care Group implementation. In the NGO-led model, the Promoter supervised between 5-9 Care Groups, which consisted of approximately 50-90 CGVs in total. The Promoter facilitated all Care Group meetings and was expected to supervise at least one CGV from each Care Group every month. Supervision consisted of accompanying the CGV on a household visit, reviewing her reporting forms, and providing feedback. In the MOH-led model, each CHW supervised between 1-3 Care Groups, which consisted of approximately 10-30 CGVs in total. The CHW facilitated all Care Group meetings and was also expected to supervise at least one CGV from each Care 
Table 1. Summary of Key Differences in NGO-led and MOH-led Care Group Models

\begin{tabular}{|c|c|c|}
\hline & Comparison Area (NGO-led Care Groups) & Intervention Area (MOH-led Care Groups) \\
\hline $\begin{array}{l}\text { Ratio of } \\
\text { Supervisors to } \\
\text { Care Groups }\end{array}$ & 1 Promoter: 5-9 Care Groups & 1 CHW: 1-3 Care Groups \\
\hline $\begin{array}{l}\text { Training } \\
\text { Methodologies }\end{array}$ & $\begin{array}{l}\text { Promoters train Care Group Volunteers during the } \\
\text { twice-monthly Care Group meetings }\end{array}$ & $\begin{array}{l}\text { NGO staff provide quarterly one-day Training of Trainers to the District } \\
\text { Health Team on three months' worth of BCC modules. The District Health } \\
\text { Team then cascades these trainings down through the MOH system as } \\
\text { follows: } \\
\text { - The District Health Team provides quarterly one-day trainings to the } \\
\text { health facility nurses on the same modules } \\
\text { - MOH nurses train the CHWs within their health facility catchment areas } \\
\text { on those same topics on a monthly basis } \\
\text { - CHWs provide that same training to their Care Groups during their } \\
\text { twice-monthly Care Group meetings }\end{array}$ \\
\hline Supervision & $\begin{array}{l}\text { Care Group Volunteers are supervised by Promoters, } \\
\text { who are in turn supervised by senior project staff }\end{array}$ & $\begin{array}{l}\text { Supervision structure is through } \mathrm{MOH} \text { system: } \\
\text { - CHWs supervise Care Group Volunteers } \\
\text { - CHWs are supervised by the nurse at each health facility }\end{array}$ \\
\hline
\end{tabular}

Group every month. The head nurse in turn supervised the CHW by attending at least one Care Group meeting per month, reviewing the $\mathrm{CHW}$ Care Group reporting forms and providing feedback. In addition, the head nurse facilitated a monthly meeting with all CHWs at the health facility, during which the CHWs submit their monthly Care Group reports and the nurses reviewed and provided support in resolving any problems related to Care Group implementation.

\section{Data collection methods}

Quantitative data were collected before the intervention (September-November 2010) and after the intervention (June 2013) from among 593 and 700 mothers of children age 0-23 months, respectively. A census of all households with children 0-23 months in Bukinanyana Commune was conducted in July 2010 (baseline) and April 2013 (endline). The census identified 14,433 households with children 0-23 months, which constituted the sampling frame for the study and allowed us to take a simple random sample, with the household as the sampling unit. The baseline and endline sample size were calculated to detect a difference of $10 \%$ between the two intervention groups for each indicator being considered (one-sided alpha 0.05 , beta $80 \%$ ). Each randomly selected household was visited up to three times. The 16 enumerators at baseline consisted of project and $\mathrm{MOH}$ staff. Of the 21 enumerators at endline, 11 were project staff and 10 were external enumerators selected from the local community. Care was taken to ensure project staff were not serving as enumerators within their assigned project area.

\section{Intervention monitoring}

Four process indicators were collected on a monthly basis to monitor Care Group activities in both study areas: the average number of Care Group meetings per month, CGV attendance at Care Group meetings, household visitation rates, and CGV reporting rates. In addition, a qualitative mid-term process evaluation was conducted to prospectively document the implementation and the functionality of the two Care Group models, as well as perceptions of the $\mathrm{MOH}$-led and NGO-led models from $\mathrm{MOH}$ personnel and community members. A total of 15 focus group discussions (FGDs) were completed with mothers of children 0-23 months, Care Group Volunteers, CHWs, health facility nurses, Health Management Committee members, local leaders, and NGO Care Group supervisors (Promoters). The FGDs were grouped by participant category and by study area. In-depth interviews were also conducted with two NGO staff (Promoters) and one member of the District Health Team.

\section{Definition of variables}

The study assessed changes in 40 child health knowledge and practice indicators, which are grouped into four main categories:

- Preventive practices: exclusive breastfeeding until six months, hand-washing at critical times, use of insecticide-treated bed net

- Knowledge: knowledge of childhood illness danger signs, complementary feeding, and proper care of a sick child

- Care-seeking practices for child illness: careseeking and treatment for children sick with diarrhoea, fever, and acute respiratory infections

- Contact intensity: contact with trained provider of health information and participation in meetings during which child health is discussed

We sought to test whether the MOH-led Care Group model would achieve at least the same coverage of the knowledge and practice of key health and nutrition 
behaviors as the NGO-led model after two years of implementation (June 2011-May 2013).

\section{Analysis techniques}

We used Pearson's chi-squared test to evaluate whether there was a statistically significant difference in endline indicators in the intervention and comparison areas. Since this study was quasi-experimental, we also conducted a difference-in-differences (DiD) analysis $[17,18]$. To do so, we calculated the coverage rates for each of the indicators in 2010 and 2013 in both the intervention and comparison areas. The percentage increase in coverage in comparison areas was then subtracted from the percentage increase in intervention areas to obtain the difference in the differences; as summarized by the formula below:

$$
D I D(Y)=\left(\bar{Y}_{I E}-\bar{Y}_{C E}\right)-\left(\bar{Y}_{I B}-\bar{Y}_{C B}\right)
$$

where $\bar{Y}_{I E}$ and $\bar{Y}_{C E}$ represent the average outcome at endline in the intervention site and comparison area, respectively, and $\bar{Y}_{I B}$ and $\bar{Y}_{C B}$ the average outcome at baseline in the intervention site and comparison area, respectively. Given our hypothesis that the $\mathrm{MOH}$-led model performs at least as well as the NGO-led model in the achievement of key child health indicators, both the chi-squared and DiD analysis specifically sought to assess if indicators in the intervention area perform statistically significantly worse than those in the comparison area.

\section{Ethical considerations}

Ethical approval for this study was obtained from the Trinity College of Dublin Health Policy and Management's Centre for Global Health Research Ethics Committee. Informed consent was verbally obtained from each respondent prior to participating in the baseline and endline surveys as well as the FGDs and interviews during the midterm process evaluation, as the majority of respondents did not have sufficient literacy skills to provide written consent.

\section{Results}

\section{Respondent characteristics}

Table 2 presents the demographic and socio-economic characteristics of households with children aged 0-23 months in the intervention and comparison areas at baseline. Respondents in both areas were equivalent in levels of education and household composition, but there were statistically significant differences in three household economy measures: household dietary diversity, the per cent of households that work outside the home to earn money, and the per cent of households that sell their agricultural goods at the market. These indicators paint a mixed picture of economic status in the intervention and comparison groups: a more diversified diet is correlated with higher household income [19], suggesting that the comparison area might have been wealthier. This is reinforced by the fact that providing casual labor on other people's farms, which was more prevalent in the intervention area, is usually an activity in which poorer households are engaged and is sometimes considered a coping strategy [20]. Significantly more households in the comparison area sold their crops at local markets, and while households who sell cash crops are generally better off than those who rely on subsistence farming, it may also be that households sold their crops to earn cash for other non-food items; which would also be considered a coping strategy [21]. Differences in these indicators between the two study areas did not persist at endline.

\section{Intervention monitoring}

Care Groups in both the intervention and comparison areas functioned similarly throughout the study period. An average of 1.9 Care Group meetings was held per month in both study areas, largely meeting the standard of two meetings per month. Care Group Volunteer attendance was consistently high: $87 \%$ of NGO-led Care Groups and $91 \%$ of MOH-led Care Groups met the target of at least $80 \%$ CGV attendance in at least one meeting each month. NGO-led Care Groups achieved slightly higher home visitation rates, with an average of $94 \%$ of households receiving at least one visit from a CGV per month, compared with $87 \%$ in the $\mathrm{MOH}$-led Care Groups. Care Group Volunteer reporting rates were the same in both study areas, with an average of 96\% of CGVs submitting reports to their respective supervisor each month.

The mid-term process evaluation revealed two important findings related to Care Group implementation in both study areas. The first finding is related to the role of CHWs under the NGO-led Care Group model: at the beginning of the intervention, project staff oriented both health facility personnel and CHWs to the Care Group concept and encouraged their participation in Care Group activities. The process evaluation found that instead of merely participating in Care Group activities in the comparison area, CHWs were taking a more active role in Care Group meeting facilitation and reporting, effectively serving as assistants to the NGO supervisor. The process evaluation also found that, in the intervention area, supervision from the health facility level was not working as planned. In the original intervention design, the head nurse at each health facility was tasked with overseeing all Care Group activities within the health facility catchment area, through the direct supervision of the CHWs. However, the head nurse had many other responsibilities at the 
Table 2. Demographic and Socio-economic Characteristics of Households with Children Age 0-23 Months at Baseline

\begin{tabular}{|c|c|c|c|}
\hline \multirow[t]{2}{*}{ Characteristic } & Comparison Area (NGO-led Model) N = 296 & Intervention Area (MOH-led Model) N = 297 & \multirow[t]{2}{*}{ p-value } \\
\hline & $\%$ & $\%$ & \\
\hline \multicolumn{4}{|l|}{ Child's Sex } \\
\hline Male & 52.0 & 54.5 & .539 \\
\hline Female & 48.0 & 45.5 & .595 \\
\hline \multicolumn{4}{|l|}{ Child's Age } \\
\hline $0-5$ months & 14.9 & 9.8 & .075 \\
\hline 6-11 months & 25.1 & 29.0 & .333 \\
\hline $12-23$ months & 60.0 & 61.2 & .815 \\
\hline \multicolumn{4}{|l|}{ Household Composition } \\
\hline Mean \# of children 0-23 months & 1.9 & 1.8 & .297 \\
\hline \multicolumn{4}{|l|}{ Mother's Level of Education } \\
\hline Illiterate & 66.2 & 67.8 & .862 \\
\hline Basic literacy & 27.0 & 26.9 & .926 \\
\hline Completed primary school & 6.8 & 5.3 & .486 \\
\hline \multicolumn{4}{|l|}{ Household Economy } \\
\hline $\begin{array}{l}\text { Mean household dietary diversity score (total } \\
\text { of } 11 \text { food groups) }\end{array}$ & 4.65 & 4.2 & $.004^{* *}$ \\
\hline $\begin{array}{l}\text { Woman does agricultural work on other's land } \\
\text { to earn money }\end{array}$ & 17.9 & 29.3 & $.002^{* *}$ \\
\hline Woman sells crops at market to earn money & 28.7 & 16.8 & $.001^{* * *}$ \\
\hline
\end{tabular}

Abbreviations: $\mathrm{MOH}$, Ministry of Health; NGO, non-governmental organization

Notes: ${ }^{*} \mathrm{p}<.05{ }^{* *} \mathrm{p}<.01{ }^{* * *} \mathrm{p}<.001$

health facility and with the District Health Team, which left them little time to oversee community level activities. As stated by one head nurse in the intervention area, "The workload has increased a lot for the Titulaires [head nurses] because we have lots to do. If we add this [Care Group supervision] to our other responsibilities we will not be effective. Really, we don't have the time to do supervision of these activities." As such, a junior nurse at each health facility, who had fewer responsibilities and therefore had more time to supervise CHWs and their respective Care Group activities, was identified.

\section{Child health indicators}

Chi-squared testing found that 38 of the 40 indicators performed at least as well in the intervention area as in the comparison area. The DiD analysis, which accounts for difference $\mathrm{s}$ in baseline values, found that the $\mathrm{MOH}$ led model performed at least as well as the NGO-led model in 39 of 40 outcome indicators. Supplementary Tables 1 and 2 (additional files 1 and 2) provide results for all 40 indicators. In the interest of space, we report on a sub-set of 10 key dependent variables, which have a robust causal association with child mortality [22,23].

Table 3 presents the results of the chi-squared testing for the 10 key child health practices in the intervention and comparison areas at endline. Endline values for all 10 indicators were at least as high for the intervention area as the comparison area; and were statistically significantly higher for two indicators (care-seeking for all illnesses and hand-washing at critical times).

Table 4 presents the $\mathrm{DiD}$ analysis, which takes into account differences in all 10 indicators at baseline. There was a strong positive effect of the intervention on one indicator (hand washing at three of four critical times). Although the $\mathrm{DiD}$ results suggest variable positive and negative effects of the intervention in the other nine indicators, none of the other results was statistically significant. The DiD analysis therefore demonstrates that the $\mathrm{MOH}$-led model performed at least as well as the NGOled model in all 10 outcome indicators.

\section{Discussion}

\section{Summary of findings}

We found that the MOH-led Care Group model performed at least as well as the NGO-led model in achieving specific child health and nutrition outcomes. Mothers of children 0-23 months in the intervention and comparison sites reported similar levels of knowledge and practices for 38 of 40 dependent variables measured in the study, and these results remained unchanged after accounting for differences in the indicator values at baseline. Process monitoring data confirmed that the MOH-led Care Group model and the NGO-led Care Group model were implemented with similar intervention strength. 
Table 3. Key Child Health Indicators across Intervention and Comparison Areas

\begin{tabular}{|c|c|c|c|c|c|c|}
\hline \multirow[t]{2}{*}{ Indicator } & \multirow[b]{2}{*}{$\mathrm{N}$} & \multicolumn{2}{|c|}{$\begin{array}{l}\text { Comparison } \\
\text { Area (NGO- } \\
\text { led Model) }\end{array}$} & \multicolumn{2}{|c|}{$\begin{array}{l}\text { Intervention } \\
\text { Area (MOH- } \\
\text { led Model) }\end{array}$} & \multirow[t]{2}{*}{ p-value } \\
\hline & & $\%$ & $\mathrm{~N}$ & $\%$ & & \\
\hline $\begin{array}{l}\text { Exclusive } \\
\text { breastfeeding }\end{array}$ & $\begin{array}{l}\text { Percent of children age } 0-5 \text { months who consumed only breast milk within the } 24 \\
\text { hours preceding the survey }\end{array}$ & 51 & 92.2 & 59 & 91.5 & .904 \\
\hline Dietary diversity & $\begin{array}{l}\text { Percent of breastfed children age } 6-23 \text { months who consumed foods from four or } \\
\text { more food categories (from a total of eight) within the } 24 \text { hours preceding the survey }\end{array}$ & 267 & 52.1 & 263 & 55.9 & .279 \\
\hline $\begin{array}{l}\text { Knowledge of } \\
\text { complementary } \\
\text { feeding }\end{array}$ & $\begin{array}{l}\text { Percent of mothers of children age } 0-23 \text { months who correctly identify six months as } \\
\text { the appropriate age at which to introduce any other foods or liquids other than } \\
\text { breast milk }\end{array}$ & 347 & 86.5 & 353 & 90.1 & .135 \\
\hline ORT use & $\begin{array}{l}\text { Percent of children age } 0-23 \text { months with diarrhea in the two weeks preceding the } \\
\text { survey who received ORS and/or recommended home fluids }\end{array}$ & 66 & 89.4 & 53 & 92.5 & .567 \\
\hline $\begin{array}{l}\text { Prompt anti-malarial } \\
\text { treatment }\end{array}$ & $\begin{array}{l}\text { Percent of children age } 0-23 \text { months with fever in the two weeks preceding the } \\
\text { survey who were treated with an effective anti-malarial drug within } 24 \text { hours after the } \\
\text { fever began }\end{array}$ & 159 & 17 & 166 & 20.5 & .419 \\
\hline $\begin{array}{l}\text { ARI care-seeking and } \\
\text { treatment }\end{array}$ & $\begin{array}{l}\text { Percent of children age } 0-23 \text { months with cough and fast/difficult breathing in the } \\
\text { two weeks preceding the survey who were taken to a health facility or received } \\
\text { antibiotics from an alternative source }\end{array}$ & 154 & 88.3 & 143 & 92.3 & .246 \\
\hline $\begin{array}{l}\text { Care-seeking all } \\
\text { illnesses }\end{array}$ & $\begin{array}{l}\text { Percent of children age } 0-23 \text { months with diarrhea, fever, or ARI symptoms in the two } \\
\text { weeks preceding the survey whose caregivers sought care or advice outside the } \\
\text { home }\end{array}$ & 234 & 86.3 & 229 & 93.4 & $.011^{*}$ \\
\hline $\begin{array}{l}\text { Hand washing at } \\
\text { critical times }\end{array}$ & $\begin{array}{l}\text { Percent of caregivers of children age } 0-23 \text { month who reported washing their hands } \\
\text { with soap during at least three of four critical times (before preparing food, before } \\
\text { feeding a child, after defecation, after attending to a child who has defecated) in the } \\
\text { previous } 24 \text { hours }\end{array}$ & 347 & 22.8 & 352 & 34.7 & $.001^{* * *}$ \\
\hline ITN use & Percent of children age 0-23 months who slept under an ITN the previous night & 344 & 32 & 352 & 34.9 & .407 \\
\hline Contact intensity & $\begin{array}{l}\text { Percent of mothers of children age } 0-23 \text { months with at least two personal contacts } \\
\text { with a trained provider or health information in the previous month }\end{array}$ & 347 & 77.5 & 353 & 79.3 & .563 \\
\hline
\end{tabular}

Abbreviations: ARI, acute respiratory infection; ITN, insecticide-treated bed net; $\mathrm{MOH}$, Ministry of Health; NGO, non-governmental organization; ORT, oral rehydration therapy.

Notes: ${ }^{*} \mathrm{p}<.05 * * \mathrm{p}<.01{ }^{* * *} \mathrm{p}<.001$

Table 4. Difference-in-Differences Analysis for Key Child Health Indicators

\begin{tabular}{|c|c|c|c|c|c|c|c|c|c|c|c|}
\hline \multirow[t]{3}{*}{ Indicator } & \multicolumn{5}{|c|}{$\begin{array}{c}\text { Comparison Area (NGO-led } \\
\text { Model) }\end{array}$} & \multicolumn{5}{|c|}{$\begin{array}{c}\text { Intervention Area (MOH-led } \\
\text { Model) }\end{array}$} & \multirow{3}{*}{$\begin{array}{c}\text { Difference in the Differences } \\
\% \\
\end{array}$} \\
\hline & \multicolumn{2}{|c|}{$\begin{array}{l}\text { Baseline } \\
(2010)\end{array}$} & \multicolumn{2}{|c|}{$\begin{array}{l}\text { End line } \\
(2013)\end{array}$} & \multirow{2}{*}{$\begin{array}{c}\text { Change } \\
\% \\
\end{array}$} & \multicolumn{2}{|c|}{$\begin{array}{l}\text { Baseline } \\
\text { (2010) }\end{array}$} & \multicolumn{2}{|c|}{$\begin{array}{l}\text { End line } \\
(2013)\end{array}$} & \multirow{2}{*}{$\begin{array}{c}\text { Change } \\
\% \\
\end{array}$} & \\
\hline & $\mathrm{N}$ & $\%$ & $\mathrm{~N}$ & $\%$ & & $\mathrm{~N}$ & $\%$ & $\mathrm{~N}$ & $\%$ & & \\
\hline Exclusive breastfeeding & 44 & 36.4 & 51 & 92.2 & +55.8 & 29 & 51.7 & 59 & 91.5 & +39.8 & -16 \\
\hline Dietary diversity & 246 & 52.4 & 267 & 52.1 & -0.3 & 266 & 45.1 & 263 & 55.9 & +10.8 & +11.1 \\
\hline Knowledge of complementary feeding & 296 & 69.9 & 347 & 75.0 & +5.1 & 296 & 86.5 & 353 & 90.1 & +3.6 & -1.5 \\
\hline ORT use & 88 & 85.2 & 66 & 89.4 & +4.2 & 93 & 78.5 & 53 & 92.5 & +14 & +9.8 \\
\hline Prompt anti-malarial treatment & 90 & 12.2 & 159 & 17.0 & +4.8 & 96 & 11.5 & 166 & 20.5 & +9 & +4.2 \\
\hline ARI care-seeking and treatment & 80 & 75.0 & 154 & 88.3 & +13.3 & 65 & 80.0 & 143 & 92.3 & +12.3 & -1 \\
\hline Care-seeking all illnesses & 149 & 77.2 & 234 & 86.3 & +9.1 & 162 & 78.4 & 229 & 93.4 & +15 & +5.9 \\
\hline Hand washing at critical times & 296 & 7.8 & 347 & 22.8 & +15 & 296 & 7.4 & 352 & 34.7 & +27.3 & $+12.3^{* *}$ \\
\hline ITN use & 262 & 80.9 & 344 & 32 & -48.9 & 263 & 78.7 & 352 & 34.9 & -43.8 & +5.1 \\
\hline Contact intensity & 296 & 5.4 & 347 & 77.5 & +72.1 & 296 & 8.8 & 353 & 79.3 & +70.5 & -1.6 \\
\hline
\end{tabular}

Abbreviations: ARI, acute respiratory infection; ITN, insecticide-treated bed net; $\mathrm{MOH}$, Ministry of Health; NGO, non-governmental organization; ORT, oral rehydration therapy.

Notes: $* * 0.01$ 


\section{Implications for the scale-up of community-based literventions through $\mathrm{MOH}$ systems}

Ministries of Health in several countries have adopted large-scale community health initiatives that include a role for one or two CHWs in each village to generate demand for health services and expand coverage of key child health preventive practices. [24-26]. However, even relatively small villages have target populations that make it difficult for one volunteer CHW to realistically conduct monthly household visitation, especially in settings like Burundi, where nearly $20 \%$ of the total population is under five years of age [27]. The MOH-led Care Group model demonstrates how CGVs are able to extend the reach of CHWs to achieve high coverage of interpersonal communication required for behavior change through routine, systematic household visitation through existing $\mathrm{MOH}$ systems. With each CGV responsible for up to 12 households, and approximately $10 \mathrm{CGVs}$ in one Care Group, the power of one $\mathrm{CHW}$ is multiplied to reach up to 120 households through the Care Group.

In addition to achieving higher coverage levels, the $\mathrm{MOH}$-led Care Group model builds the capacity of existing CHWs, thereby strengthening human resources within the overall health system. As CHWs train and supervise CGVs, they are simultaneously strengthening their own leadership and technical skills. Moreover, $\mathrm{CHWs}$ gain a higher status in the community as they engage in supervisory activities comparable to NGO staff. The fact that CHWs organically took on a more active role in Care Group meeting facilitation and reporting in the NGO-led model also speaks to CHWs' skills and leadership potential.

In the $\mathrm{MOH}$-led Care Group model, the primary actors responsible for facilitating Care Group activities are existing health workers within the $\mathrm{MOH}$ system. However, NGO staff still have a critical role to play in building the capacity of the $\mathrm{MOH}$ to implement the model. In the intervention area, NGO staff provided initial training to the District Health Team and health facility staff on the overall concept of Care Groups, facilitated the population census and election of CGVs, conducted formative research to inform the design of the behavior change modules used by CGVs, developed the CGV reporting tools, and provided quarterly training-of-trainers to the District Health Team on the content of those modules. As the NGO continues to support $\mathrm{MOH}$ counterparts to implement the Care Group model in additional districts and provinces, many of these responsibilities could be taken on by $\mathrm{MOH}$ actors over time. For the MOH-led model to be truly integrated into national community health systems, additional advocacy and capacity building on the model will be required at the national level.

\section{Implications for program supervision}

The MOH-led Care Group model includes a two-tier supervision structure. The CGVs are supervised by CHWs, who are in turn supervised by the assistant nurse at the health facility. CHWs reported that the additional Care Group supervision tasks lightened their work load, as the multiplying power of Care Groups enabled the CHW to effectively delegate the household visitation tasks to the CGVs. This is particularly important in countries where CHWs are increasingly asked to take on additional responsibilities beyond household visitation, such as community case management.

Another key finding of the study was the fact that the junior as well as senior nurses were able to supervise Care Groups. While it may be difficult for the $\mathrm{MOH}$ to assume Care Group supervision responsibilities if scarce mid-level human resources are required, prospects may be better if these responsibilities are tasked to under-utilized lower level human resources, such as the assistant nurses. It is possible that we overestimated the importance of mid-level human resources to supervise community-level activities; studies of task shifting in low-income countries' programs have found that lower level cadres of health workers are able to deliver and supervise quality and comparable health education, promotion, and care to communities when compared with clinical providers $[28,29]$.

For an effective implementation strategy to be scaled up, it must be cost effective and feasible for the health system to maintain. A previous evaluation of an NGOled Care Group project had an average cost of $\$ 2.78$ per beneficiary per year [30]. While an assessment of cost effectiveness is beyond the scope of this paper, the $\mathrm{MOH}-\mathrm{led}$ Care Group model does provide some cost savings to the NGO model in terms of supervisor staff salary, recruitment and transportation expenses. Our study demonstrates that the MOH-led Care Group model may be implemented using existing and underutilized human resources within the $\mathrm{MOH}$ system. Therefore, Care Group supervision costs borne by the $\mathrm{MOH}$ would therefore most likely be the opportunity costs of asking existing health workers to assume additional responsibilities and/or shift some responsibilities to lower level cadres. Future studies are required to systematically document all inputs and monetary costs borne by the $\mathrm{MOH}$ to implement the model and compare the cost effectiveness of the $\mathrm{NGO}$ and $\mathrm{MOH}$-led models.

\section{Limitations}

Statistically significant differences in socio-economic status between the study areas at baseline may have confounded the results, although the differences did not persist at endline. These differences may be partially 
explained by the fact that the study design was quasiexperimental rather than experimental, or that the baseline and endline surveys were conducted at different times of the year, October 2010 and May 2013, respectively. The rainy season lasts through October, which extends the hunger period, as food stocks are depleted and crops are not yet ready for harvest. There is usually an increase in malnutrition and malaria cases in October. Therefore, it is likely that the endline survey occurred when households were relatively better off. This does not affect the chi-square findings since this analysis was only done at endline, however it may have affected the difference-in-differences results. Using project staff and $\mathrm{MOH}$ staff as enumerators may also have biased respondent results, however care was taken to mitigate this bias by assigning enumerators to areas outside of their assigned project area.

\section{Conclusion}

The results presented in this paper point to the potential of an MOH-led Care Group model to overcome human resource constraints to achieve high coverage of community-based health interventions through existing government health systems. To fully assess the potential for sustainability of the $\mathrm{MOH}$-led model, an additional study is required to document the extent to which the $\mathrm{MOH}$ continues to support Care Group implementation as well as whether results are sustained in both the NGO-led and $\mathrm{MOH}-$ led Care Group areas. In addition, future research assessing what other typical NGO inputs could be shifted to the $\mathrm{MOH}$ and the implications of those shifts for the scale-up and sustainability of community health interventions is needed. The MOH in Burundi, specifically the District Health Team, was actively involved in designing the implementation of the $\mathrm{MOH}$-led Care Group model, and future implementers should collaborate with $\mathrm{MOH}$ counterparts to assess the most optimal way that Care Groups can be integrated into $\mathrm{MOH}$ systems.

\section{Additional material}

Additional file 1:

Additional file 2:

\section{List of abbreviations}

CGV: Care Group Volunteer; CHW: Community Health Worker; DiD: Difference in Differences; FGD: Focus Group Discussion; MOH: Ministry of Health; NGO: Non-Governmental Organization

\section{Competing interests}

The authors declare no competing interests.

\section{Authors' contributions}

JW participated in the study's design and coordination and drafted the manuscript. RM conducted all statistical analysis and helped to draft the manuscript. DS conceived of the study and participated in its design and coordination. All authors read and approved the final manuscript.

\section{Acknowledgements}

The authors wish to thank the Mabayi District Health Team as well as the health centre nurses, Community HealthWorkers, and Care Group Volunteers who were the central actors in this study and provided rich lessons and information. Joseph Jasperse and Dr. Jean Christophe Fotso of Concern Worldwide reviewed the paper, as did Dr. Henry Perry of John Hopkins University and Drs. Jim Foreit and Aparna Jain of Population Council. Alyssa Davis, former Health Advisor at Concern Worldwide Burundi, conceptualized the $\mathrm{MOH}$-led model and led its initial field implementation. The authors also thank the reviewers. This study was funded by the Office of Health, Infectious Disease and Nutrition; Bureau of Global Health, United States Agency for International Development (USAID) under the terms of Cooperative Agreement Number GHN-A-00-08-0005. The contents of this article are the responsibility of the authors and do not reflect the views of USAID or the United States Government. JW is a Health Advisor at Concern Worldwide and provided technical support to the implementation of this study. During the preparation of the manuscript, RM was a graduate student at Colombia University's Mailman School of Public Health. DS oversees all initiatives for Concern Worldwide's health and nutrition portfolio in Burundi.

\section{Declarations}

The publication costs for this article were funded by a grant from by the Office of Health, Infectious Disease and Nutrition; Bureau of Global Health, United States Agency for International Development (USAID). The contents of this article are the responsibility of the authors and do not reflect the views of USAID or the United States Government.

This article has been published as part of BMC Health Services Research Volume 15 Supplement 1, 2015: Improved access to maternal, newborn and child health services: strengthening human resources for health. The full contents of the supplement are available online at http://www. biomedcentral.com/bmchealthservres/supplements/15/S1

\section{Authors' details}

${ }^{1}$ Concern Worldwide, US, 355 Lexington Ave, $19^{\text {th }}$ Floor New York, NY 10017 , USA. ${ }^{2}$ Mailman School of Public Health, Columbia University, 722 W. 168th Street, New York, NY 10032, USA. ${ }^{3}$ Concern Worldwide, Burundi, INNS Quartier, Muyinga Avenue No. 38, Bujumbura, Burundi.

Published: 8 June 2015

\section{References}

1. Barros AJ, Ronsmans C, Axelson H, Loaiza E, Bertoldi A, Francca G, et al: Equity in maternal, newborn, and child health interventions in Countdown to 2015: a retrospective review of survey data from 54 countries. The Lancet 2012, 379(9822):1225-1233.

2. Fernandes Q, Wagenaar B, Anselmi L, Pfeiffer J, Gloyd S, Sherr K: Effects of health-system strengthening on under-5, infant, and neonatal mortality: 11-year provincial-level time-series analyses in Mozambique. The Lancet Global Health 2014, 2(8):468-477.

3. Perry H, Hodgins S, Crigler L, LeBan K: Community health worker relationships with other parts of the health system. In Developing and strengthening community health worker programs at scale: A reference guide and case studies for program managers and policy makers. Volume 12.. 1 edition. Washington, DC: USAID/MCHIP;H. Perry and L. Crigler 2014:(1):12-20.

4. Byrne A, Hodge A, Jimenez-Soto E, Morgan A: What Works? Strategies to Increase Reproductive, Maternal and Child Health in Difficult to Access Mountainous Locations: A Systematic Literature Review. PloS One 2014, 9(2):e87683.

5. Perry $H$, Zulliger R, Rogers $M$ : Community health workers in low-, middle-, and high-income countries: an overview of their history, recent evolution, and current effectiveness. Annual Review of Public Health 2014 35:399-421.

6. Davis T, Wetzel C, Avilan E, Lopes C, Chase R, Winch P, Perry H: Reducing child global undernutrition at scale in Sofala Province, Mozambique, using Care Group Volunteers to communicate health messages to mothers. Global Health: Science and Practice 2013, 35:399-421. 
7. Ricca J, Kureshy N, LeBan K, Prosnitz D, Ryan L: Community-based intervention packages facilitated by NGOs demonstrate plausible evidence for child mortality impact. Health Policy and Planning 2014, 29(2):204-216.

8. Perry H, Hodgin S, Crigley L, LeBan K: Community health worker relationships with other parts of the health system. In Developing and strengthening community health worker programs at scale: A reference guide and case studies for program managers and policy makers. Volume 12. 1 edition. Washington, DC: USAID/MCHIP;H. Perry and L. Crigler 2014:(1):12-20

9. Global Health Workforce Alliance: Community Health Workers and Universal Health Coverage: Knowledge gaps and a need based Global Research Agenda by 2015. Geneva: World Health Organization; 2013.

10. George A, Young M, Nefdt R, Basu R, Sylla M, Clarysse G, et al: Community health workers providing government community case management for child survival in sub-Saharan Africa: who are they and what are they expected to do? The American Journal of Tropical Medicine and Hygiene 2012, 87(5 Suppl 5):85-91.

11. Perry H, Ricca J, LeBan K, Morrow M: Prospects for Effective and Scalable Community-Based Approaches to Improve Reproductive, Maternal, Newborn and Child Health: A Summary of Experiences from the Maternal and Child Health Integrated Program and the Child Survival and Health Grants Program and a Review of the Evidence. Washington, DC: USAID/MCHIP; 2014.

12. Davis TP Jr, Wetzel C, Hernandex Avilan E, de Mendoza Lopes C, Chase RP, Winch PJ, et al: Reducing child global undernutrition at scale in Sofala Province, Mozambique, using Care Group Volunteers to communicate health messages to mothers. Global Health: Science and Practice 2013, 1(1):35-51.

13. Edwar A, Ernst P, Taylor C, Becker S, Mazive E, Perry H: Examining the evidence of under-five mortality reduction in a community-based programme in Gaza, Mozambique. Transactions of the Royal Society of Tropical Medicine and Hygiene 2007, 101(8):814-822

14. Yamey G: What are the barriers to scaling up health interventions in low and middle income countries? A qualitative study of academic leaders in implementation science. Globalization and Health 2012, 8:11.

15. Food Security and Nutrition Network Social and Behavioral Change Task Force: Care Groups: A Training Manual for Program Design and Implementation. Washington, DC: Technical and Operational Performance Support Program; 2014.

16. Establishing Care Group Criteria. 2010 [http://www.caregroupinfo.org/ docs/Care_Group_Criteria_November_12_2010.pdf].

17. Heckman JJ: The Scientific Model of Causality. Sociological Methodology 2005, 35(1):1-97

18. Meyer BD: Natural and Quasi-experiments in Economics. Journal of Business \& Economic Statistics 1995, 13(2):151-161.

19. Food and Nutrition Technical Assistance Project: Household Dietary Diversity Score for Measurement of Household Food Access: Indicator Guide (v.2). Washington, DC: Academy for Educational Development; 2011.

20. Eriksen S, Silva J: The Vulnerability Context of a Savanna area in Mozambique: Household Drought Coping Strategies and Responses to Economic Change. Environmental Science \& Policy 2009, 12(1):33-52.

21. McAlpine K: Contextual Analysis of Cibitoke Burundi. Dublin: Concern Worldwide; 2011

22. Jones G, Steketee RW, Black RE, Bhutta ZA, Morris SS, Bellagio Child Survival Study Group: How Many Child Deaths Can We Prevent This Year? The Lancet 2003, 362(9377):65-71.

23. Ricca J, Kureshy N, LeBan K, Prosnitz D, Ryan L: Community-based intervention packages facilitated by NGOs demonstrate plausible evidence for child mortality impact. Health Policy and Planning 2014 29(2):204-216.

24. Ministry of Health and Population: Nepal Health Sector ProgrammeImplementation Plan II 2010 - 2015. 2009 [http://www.nhssp.org.np/ health_policy/Consolidated\%20NHSP-2\%20IP\%20092812\%20QA.pdf].

25. Ministry of Health: National Community Health Strategic Plan July 2013June 2018.[http://www.nationalplanningcycles.org/sites/default/files/ country_docs/Rwanda/chd-strategic_plan.pdf].

26. Ministry of Health: National Community Health Worker Strategy in Zambia. [http://www.advancingpartners.org/sites/default/files/cadres/ policies/Zambia_NCHW\%20Strategy-August-\%202010\%20Final.pdf].
27. Ministere des Finances et de la Planification du Developpement Economique, Institute de Statistiques et d'Etudes Economiques du Burundi: Annuaire Statistique du Burundi. 2011 [http://www.isteebu.bi/images/ annuaires/annuaire\%202011.pdf\%20vf.pdf].

28. McPake B, Mensah K: Task Shifting in Health Care in Resource-poor Countries. The Lancet 2008, 372(9642):870-871.

29. Lehmann U, Van Damme W, Barten F, Sanders D: Task Shifting: The Answer to the Human Resources Crisis in Africa? Human Resources for Health 2009, 7:49.

30. Perry H: Expanded Impact Child Survival Program Final Evaluation Report; Sofala Province, Mozambique. 2010.

doi:10.1186/1472-6963-15-S1-S2

Cite this article as: Weiss et al:: Shifting management of a community volunteer system for improved child health outcomes: results from an operations research study in Burundi. BMC Health Services Research 2015 15(Suppl 1):S2.

\section{Submit your next manuscript to BioMed Central and take full advantage of:}

- Convenient online submission

- Thorough peer review

- No space constraints or color figure charges

- Immediate publication on acceptance

- Inclusion in PubMed, CAS, Scopus and Google Scholar

- Research which is freely available for redistribution
Biomed Central 